\title{
Blockchain in Smart Cities: Exploring Possibilities in Terms of Opportunities and Challenges
}

\author{
Raed A. Salha1, Maher A. El-Hallaq², Abdelkhalek I. Alastal' \\ ${ }^{1}$ Geography and GIS Department, Arts College, Islamic University of Gaza, Gaza, Palestine \\ ${ }^{2}$ Civil Engineering Department, Engineering College, Islamic University of Gaza, Gaza, Palestine \\ Email: msalha@iugaza.edu.ps, mhallaq@iugaza.edu.ps, abdelkhalek.alastal@gmail.com
}

How to cite this paper: Salha, R.A., El-Hallaq, M.A. and Alastal, A.I. (2019) Blockchain in Smart Cities: Exploring Possibilities in Terms of Opportunities and Challenges. Journal of Data Analysis and Information Processing, 7, 118-139. https://doi.org/10.4236/jdaip.2019.73008

Received: July 1, 2019

Accepted: August 12, 2019

Published: August 15, 2019

Copyright $\odot 2019$ by author(s) and Scientific Research Publishing Inc. This work is licensed under the Creative Commons Attribution International License (CC BY 4.0). http://creativecommons.org/licenses/by/4.0/

\begin{abstract}
The ultimate aim of a smart city is to enhance the quality of life for its residents and businesses through modern technologies in order to reduce resource deterioration and maintain overall costs. From this perspective, blockchain is one of these technologies that has received much attention during the recent years as it offers new alternatives for individuals and institutions in the smart city context. This study aims to explore the potential and contribution of blockchain in smart cities by studying and reviewing the literature of scientific research on the concept and fundamentals of blockchain, involving its most practical applications. In addition, it summarizes worldwide examples of success in using blockchain as well as exploring the challenges and opportunities related to this technology in smart cities. Thus, this study provides a useful reference for researchers to review all about the new blockchain technology.
\end{abstract}

\section{Keywords}

Blockchain Technology, Consensus, Distributed Ledger, Smart Cities, Smart Contracts

\section{Introduction}

The smart city concept can be looked upon as a framework for realization implementing a vision of advanced and modern urbanization. Smart cities control technology and utilize existing and planned infrastructure investments to provide a higher quality of living to residents and a conducive investment climate for businesses and to maximize resource utilization and transparency for governments. Smart cities can be considered an organic integration of systems, IT 
infrastructure, physical infrastructure, and social and business infrastructure. These systems work collectively so as to generate intelligent and actionable information for decision makers [1]. Incorporating new technologies into the development of smart cities means rethinking the way different services provided. From this perspective, blockchain might represent the future of both smart cities and smart communities as it offers new alternatives for individuals and institutions [2]. The blockchain emerges as an innovative tool which proves to be useful in a number of application scenarios. A number of large industrial players, such as IBM, Microsoft, Intel, and NEC, are currently investing in exploiting the blockchain in order to enrich their portfolio of products [3]. The innovation and imbalance driven by blockchain provide a great opportunity for countries and cities. Blockchain technology can help to the remodeling of the economy reshape of smart cities, society and public institutions, but it is still new and experimental [4]. The application of blockchain technology varies from city to city, from project to project, depending on economic and social conditions, infrastructure, technical expertise, and other factors.

The main objective of this study is to explore the potential and contribution of blockchain in smart cities by studying the literature of scientific research on the concept and fundamentals of the blockchain, as well as to show the most practical applications of this new technology involving some worldwide examples of success in applying it. In addition, it tries to explore the challenges and opportunities related to this new technology in smart cities.

\section{Previous Studies}

There are many studies conducted about smart cities regarding their concepts, their components, their tools and how to establish a smart city [5]-[12]. Mainly in the Palestinian Territories, Alastal et al. [13] try to promote sustainable urban development by adopting the smart city approach by identifying the concept of smart cities in the reality of the cities of the Gaza Strip, considering Khan Younis city as a case study. The study reveals that Khan Younis has $41.7 \%$ of the characteristics features of the smart city and needs further improvements in all axes especially the availability of social and economic infrastructures. El-Hallaq et al. [14] aim to promote sustainable urban development through the adoption of smart city approaches using the city's 3D representation and analysis capabilities to reflect and define the current situation and formulate a future vision using GIS and BIM. In this study, a 3D GIS/BIM model is developed for Sheikh Hamad city in the Gaza Strip as an example. In addition to, a web-based application is launched to assist in sharing, viewing, managing, analyzing and supporting decision-making process.

As our world becomes increasingly digital, we need technology that can scale it while providing the necessary security, trust, and accountability. It is believed that blockchain might be is that technology. For example, blockchain is mainly perceived through its linkage with Bitcoin, but recent developments have started 
exploring the idea of using it for financial transactions, logistics and securing contracts. Tapscott D. and Tapscott A. [15] have acknowledged the potential the blockchain revolution on redefining the idea of trust in both digital and local communities. Penzes [16] considers that the fundamental concept that can enable the combination of BIM and blockchain technology is their shared ability to serve as a single source of truth. BIM can combine information from the blockchain, such as supply chain information, the provenance of materials, payment details, etc., particularly during construction; and, it can also assign information to the blockchain, like design decisions, source of data or model modification orders. This information can later be used by smart contracts to initiate further action, such as payments or material orders. Shen and Pena-Mora [17] present and organize use cases from 159 selected papers into nine sectors recognized as crucial for sustainable and smart urban future. At the micro-level, they identify a component-based framework and analyze the design and prototypes of blockchain systems studied in a subset of 71 papers. The high-level use case review allows illustrating the relationship between them and the four pillars of urban sustainability; social, economic, environmental, and governmental. Moreover, the system level analysis helps highlight interesting inconsistencies between well-known blockchain applicability decision rules and the approaches taken by the literature. Pieroni et al. [18] consider that the integration of different technologies and different IT systems, needed to build smart city applications and services, remains the most challenge to overcome. In the smart city context, it intends to investigate the smart environment pillar, and in particular, the aspect related to the implementation of a smart energy grid for citizens in the urban context. The innovative characteristic of the proposed solution consists of using the blockchain technology to join the grid, exchanging information, and buy/sell energy between the involved nodes (energy providers and private citizens), using the blockchain granting ledger. Yannis [19] tries to explore the blockchain technology and its related platforms. It presents existing global and governmental initiatives, together with potential applications of blockchain in different domains, with a focus on education. The need to learn about this emerging technology is discussed, together with pioneering cases in formal and informal learning settings. While Ref. [20] points out that the blockchain technology in that it is focused on decentralization and in terms of functioning is transparent can help increase the value of a smart city. From its implementation of electricity transactions to natural resource management, this technology can always find its place in the development priorities of new cities based on smart grid systems.

\section{Smart City}

Actually, the improvement of the Quality of Life (QoL) and the enhancement of the Quality of Services (QoS) represent the main goal of every city evolutionary process [18]. Nowadays, most attention is paid by various cities among the world through focusing on modern technologies as well as aiming to reduce costs, use 
resources optimally, and create a more livable urban environment [21], which is known as the smart city.

\subsection{Smart City Definition}

Actuality, there is no standardized commonly accepted definition of a smart city. Various definitions of a smart city are summarized in Table 1. We can say that there are significant differences between smart city definitions, by specialization, angle of view, and the elements that smart cities address. It means that the concept

Table 1. Basic definitions for a smart city.

\begin{tabular}{|c|c|c|}
\hline s. & Definition & Field \\
\hline 1 & $\begin{array}{l}\text { A smart sustainable city is a city well performing in } 6 \text { characteristics, } \\
\text { built on the "smart" combination of endowments and activities of } \\
\text { self-decisive, independent and aware citizens [22]. }\end{array}$ & $\begin{array}{c}\text { Economic growth, } \\
\text { transport, mobility, } \\
\text { environment, standard of } \\
\text { living, governance }\end{array}$ \\
\hline
\end{tabular}

A smarter city uses technology to transform its core systems and optimize finite resources. At the highest levels of maturity, a smarter city is a knowledge-based system that provides real-time insights to

2 stakeholders and enables decision makers to manage the city's subsystems proactively. Effective information management is at the heart of this capability, and integration and analytics are the key enablers [23].

Based on the exploration of a wide and extensive array of literature from various disciplinary areas we identify eight critical factors of

3 smart city initiatives: management and organization, technology, governance, policy context, people and communities, economy, built infrastructure, and natural environment [24].

Technology

A smart city is a city that has developed some technological infrastructure that enables it to collect, aggregate and analyze real-time data and has made a concerted effort to use that data to improve the lives of its residents. Smart city initiatives often involve

4 three components: information and communication technologies (ICTs) that generate and aggregate data; analytical tools which convert that data into usable information; and organizational structures that encourage collaboration, innovation and the application of that information to solve public problems [25].

A smart city is a designation given to a city that incorporates information and communication technologies (ICT) to enhance the quality and performance of urban services such as energy, transportation and utilities to reduce resource consumption, wastage and overall costs. The overarching aim of a smart city is to enhance the quality of living for its citizens through technology. And how power of Blockchain can impact the functioning of a smart city. An approach is being presented on how Blockchain can be used on a smart city services platform to enable businesses and companies to participate in the smart city environment [26].

The use of smart computing technologies to make the critical infrastructure components and services of a city - which include

6 city administration, education, healthcare, public safety, real estate, transportation, and utilities -more intelligent, interconnected, Technology, services, efficiency and effectiveness [27].

Technology, governance, policy context, people and communities, economy, infrastructure, and the natural environment

Technology, organizational structures, collaboration, innovation

Technology, urban services, transportation, citizens, quality of living, blockchain 
of the sustainable smart city extends to include a number of important elements including vision, solutions, integration, cooperation, and continuity. It can be said that the second definition may be the most comprehensive and clearest one.

\subsection{Smart City Characteristics}

Table 2 illustrates six characteristics of a smart city and their assigned factors; smart economy, smart people, smart governance, smart mobility, smart environment and smart living. Smart economy includes factors all around economic competitiveness as innovation, entrepreneurship, trademarks, productivity and flexibility of the labor market as well as the integration in the (inter-)national market. Smart people is not just described by the level of qualification or education of the citizens but also by the quality of social interactions regarding integration and public life and the openness towards the "outer" world. Smart governance comprises aspects of political participation, services for citizens as well as the functioning of the administration. The other three characteristics and their corresponding elements are listed in Table 2. The next section will address the blockchain technology in terms of definitions, components, types, characteristics and main requirements, and other key elements related to the blockchain environment in a smart city.

\section{Blockchain Technology}

Blockchain is enabling a smart city to leverage all the advantages of cloud computing while the blockchain assessment and implementation: flexibility, agility, capex-free, compliance, scalability, allowing the smart city to deal with decentralized blockchain network concurrently. A time can be saved in creating blocks, managing a blockchain network, designing the network, and the developing applications, swiftly pool and validate use cases as well as rapidly scale and roll out blockchain based services. The following subsections review the most important elements of blockchain technology.

\subsection{Blockchain Definition}

It can be said that blockchain is a technology that is still under development, characterized by diversity and rapid development. There is no universally agreed-upon definition for blockchain. However, many of the best definitions emphasize a public, digital, chronological and distributed ledger for transactions. Where it interferes with most academic and practical specializations, and therefore different definitions of different specializations and how to deal with it are shown in Table 3.

\subsection{Blockchain Versions}

There are multiple versions of blockchain; the first version is blockchain 1, and the recent version is blockchain 4 . These versions have different aspects in terms of technology, uses, and applications. Figure 1 provides an abbreviation for various versions of blockchain. 
Table 2. Smart city characteristics [22].

\begin{tabular}{|c|c|}
\hline $\begin{array}{l}\text { Smart Economy } \\
\text { (competitiveness) }\end{array}$ & $\begin{array}{c}\text { Smart People } \\
\text { (social and human capital) }\end{array}$ \\
\hline $\begin{array}{l}\text { - Innovative spirit } \\
\text { - Entrepreneurship } \\
\text { - Economic image \& trademarks } \\
\text { - Productivity } \\
\text { - Flexibility of labor market } \\
\text { - International embeddedness } \\
\text { - Ability to transform }\end{array}$ & $\begin{array}{l}\text { - Level of qualification } \\
\text { - Affinity to lifelong learning } \\
\text { - Social and ethnic plurality } \\
\text { - Flexibility } \\
\text { - Creativity } \\
\text { - Cosmopolitanism/open mindedness } \\
\text { - Participation in public life }\end{array}$ \\
\hline $\begin{array}{l}\text { Smart Governance } \\
\text { (participation) }\end{array}$ & $\begin{array}{c}\text { Smart Mobility } \\
\text { (transport and ICT) }\end{array}$ \\
\hline $\begin{array}{l}\text { - Participation in decision-making } \\
\text { - Public and social services } \\
\text { - Transparent governance } \\
\text { - Political strategies \& perspectives }\end{array}$ & $\begin{array}{l}\text { - Local accessibility } \\
\text { - (Inter-)national accessibility } \\
\text { - Availability of ICT-infrastructure } \\
\text { - Sustainable, innovative and safe transport systems }\end{array}$ \\
\hline $\begin{array}{l}\text { Smart Environment } \\
\text { (natural resources) }\end{array}$ & $\begin{array}{l}\text { Smart Living } \\
\text { (quality of life) }\end{array}$ \\
\hline $\begin{array}{l}\text { - Attractively of natural conditions } \\
\text { - Pollution } \\
\text { - Environmental protection } \\
\text { - Sustainable resource management }\end{array}$ & $\begin{array}{l}\text { - Cultural facilities } \\
\text { - Health conditions } \\
\text { - Individual safety } \\
\text { - Housing quality } \\
\text { - Education facilities } \\
\text { - Touristic attractively } \\
\text { - Social cohesion }\end{array}$ \\
\hline
\end{tabular}

Table 3. Blockchain and distributed ledger technology (DLT) definitions.

\begin{tabular}{cl}
\hline Author & \multicolumn{1}{c}{ Definition } \\
\hline $\begin{array}{c}\text { Robby and } \\
\text { Alexander [28] }\end{array}$ & $\begin{array}{l}\text { Blockchain is a particular type or subset of so-called distributed ledger } \\
\text { technology. DLT is a way of recording and sharing data across multiple data } \\
\text { stores (also known as ledgers), which each have the exact same data records and } \\
\text { are collectively maintained and controlled by a distributed network of computer } \\
\text { servers, which are called nodes. } \\
\text { Blockchain technology enables the creation of a decentralized environment, } \\
\text { where the cryptographically validated transactions and data are not under the }\end{array}$ \\
Holotescu [29] & $\begin{array}{l}\text { control of any third party organization. Any transaction ever completed is } \\
\text { recorded in an immutable ledger in a verifiable, secure, transparent and } \\
\text { permanent way, with a timestamp and other details. }\end{array}$ \\
Bahga and & $\begin{array}{l}\text { Blockchain is a distributed data structure comprising a chain of blocks. } \\
\text { Blockchain acts as a distributed database or a global ledger which maintains } \\
\text { records of all transactions on a Blockchain network. }\end{array}$ \\
UK Government & $\begin{array}{l}\text { Distributed ledgers are a type of database that is spread across multiple sites, } \\
\text { countries or institutions, and is typically public. Records are stored one after the } \\
\text { other in a continuous ledger, rather than sorted into blocks, but they can only be } \\
\text { added when the participants reach a quorum. }\end{array}$ \\
\hline
\end{tabular}

\subsection{Blockchain Components}

Blockchain technology can seem complex; however, few of people truly and fully understand or can actually describe with certainty the basic components of blockchain technology. This most likely also holds true for cross-disciplinary researchers 


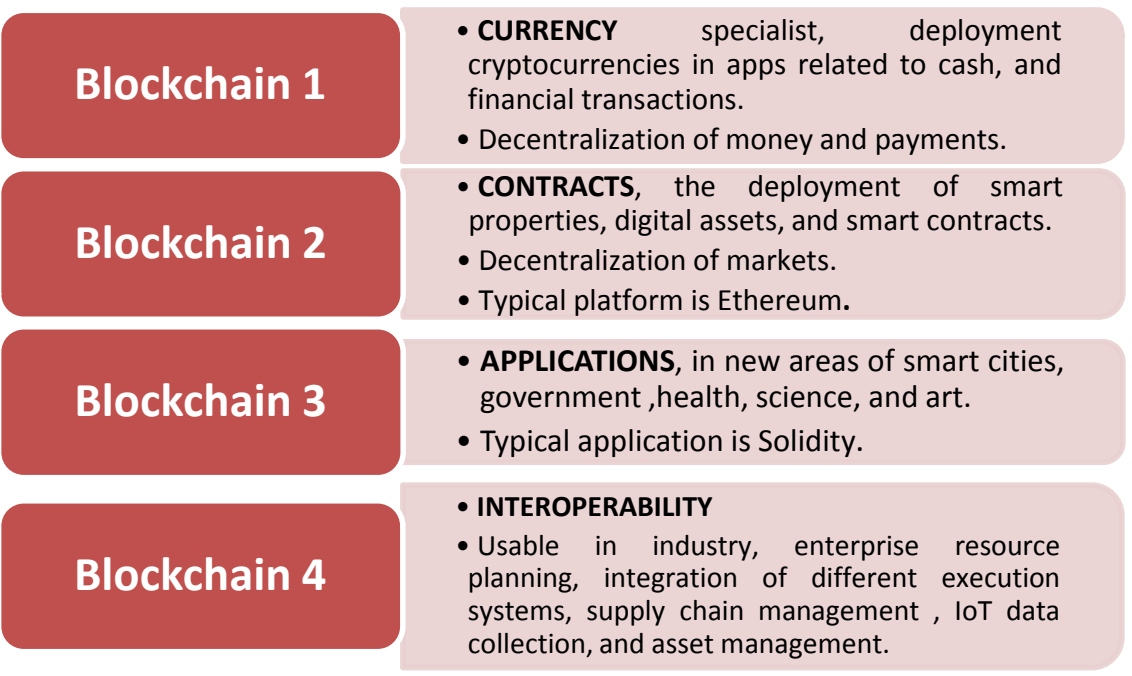

Figure 1. Blockchain versions [19].

from non-technical disciplines. Reasons might be the complex interplay of blockchain components and resulting properties that are hard to grasp in detail and the lack of a solid common knowledge base [29]. Figure 2 illustrates the core components that include the blockchain and its environment.

\subsection{Blockchain Structure}

Blockchain is a sequence of blocks that hold all transaction records in a blockchain network. Assume four transactions namely: A, B, C and D as described in Figure 3, each block contains a block header and block body. Block header contains the following [33]:

- Block version: refers to the rules of validation based on a set of blocks.

- Parent block hash: contains the hash value which indicates the previous block.

- Merkle tree root hash: the hash value of all the transactions in the block.

- Timestamp: refers to the timestamp by seconds currently.

- $N$-Bits: includes the existing hashing target in a compact format.

- Nonce: a 4-byte field, which usually starts with 0 and increases for every hash calculation.

There are three main types of blockchain platforms [34]: public, private and consortium. Organizations use these platforms based on their specific needs and it includes three formative mechanisms and structure as in Figure 4. The difference [35] in the structure, functions, nature, mechanisms, and use of the three types of blockchain can be noticed as in Table 4. Where:

- Public. Everyone can check the transaction and verify it.

- Consortium: It refers to the node that had authority can be chosen in advance, usually has partnerships like business to business, the data in a blockchain can be open or private, can be seen as Partly Decentralized as Hyperledger. 


\section{CRYPTOGRAPHY}

Use of a variety of cryptographic techniques including cryptographic one way hash functions, Merkle trees and public key infrastructure (private-public key pairs).

\section{CONSENSUS MECHANISM}

Algorithm that determines the ordering of transactions in an adversarial environment (i.e., assuming not every participant is honest).

\section{P2P NETWORK}

Network for peer discovery and data sharing in a peerto-peer fashion.

\section{Blockchain}

Components

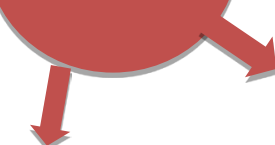

\section{LEDGER}

List of transactions bundled together in cryptographically linked 'blocks').

\section{VALIDITY RULES}

Common set of rules of the network (i.e., what transactions are considered valid, how the ledger gets updated, etc.).

Figure 2. The main components of Blockchain [32].

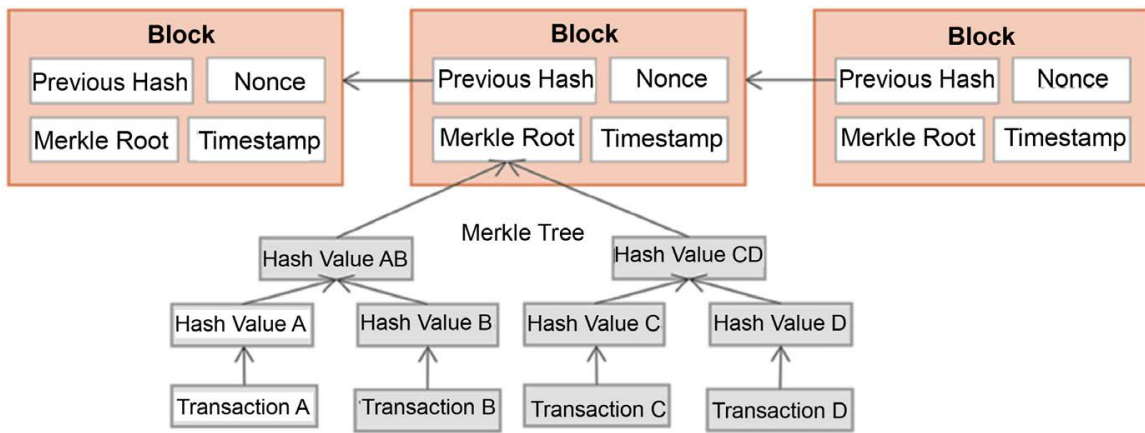

Figure 3. Blockchain structure and its components [26].

\section{Distributed Network}

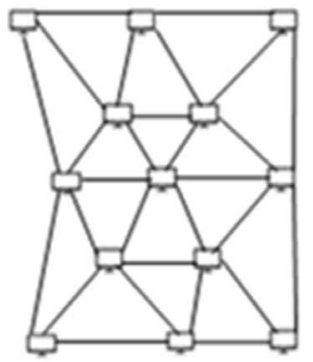

(a)
Decentralized Network

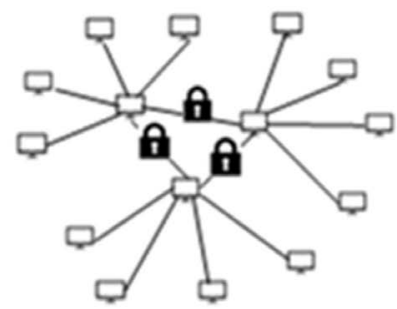

(b)
Centralized

Network

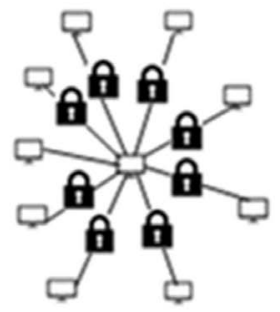

(c)

Figure 4. Blockchain network types: (a) Public; (b) Consortium; and (c) Private.

- Private: It refers to not every node can participate, maybe one or more restricted in the constructed blockchain. That interpretation of the firm authority for access to data management. 
Table 4. Comparison between blockchain types.

\begin{tabular}{cccc}
\hline & Public & Private & Consortium \\
\hline Structure & Decentralized & Centralized & Partially decentralized \\
Access & Open Read/Write & Permissioned & Permissioned \\
Speed & Slower ( 10 minutes) & $\begin{array}{c}\text { Faster (Same as a } \\
\text { transactional system) }\end{array}$ & $\begin{array}{c}\text { Vary by the number of } \\
\text { nodes }\end{array}$ \\
Consensus & $\begin{array}{c}\text { Proof of work proof of } \\
\text { stake }\end{array}$ & Pre-approved & Pre-approved \\
Identity & Anonymous & Known identities & Known identities \\
Use Cases & Crypto economy & Reference data management & Secure data sharing \\
Examples & Bitcoin, Ethereum, Dash & MONAX, Multichain & R3 (Banks), EWF (Energy) \\
\hline
\end{tabular}

\subsection{Consensus Methods}

Blockchains are peer-to-peer networks with no central administrator or authority. It is crucial to ensure that the network participants reach consensus on the state of the ledger i.e. the uniqueness and order of records. This is done through consensus algorithms that apply different methods to ensure that the right order and uniqueness of transactions have been determined and validated by enough users to be added to the ledger. Figure 5 illustrates the consensus methods [36].

\subsection{Artificial Intelligence (AI)}

Blockchain Technology powered by AI is the most advanced IT development taking place in the blockchain and cryptocurrency market, for example. AI provides several features to manage decentralized monetary systems. AI algorithms can be used to predict the value of Bitcoins, which can help Bitcoin traders to manage Bitcoin transactions. It will also help the customers to have easy access to comparative information and will allow investors to be better informed before making decisions about their financial plans [37]. Artificial intelligence will be effective through its use of smart networks in various smart sectors of the city; to achieve more efficiency and effectiveness in the delivery of different services, as well as the use of AI in finding the mechanisms of consensus used in the implementation of transactions for users in different types of blockchain and also in different scenarios and operations in the smart city.

\subsection{Smart Contracts}

Smart contracts are effectively small computer programs stored on a blockchain, which will perform a transaction under specified conditions. Thus, a smart contract is typically a declaration such as "transfer $\mathrm{X}$ to $\mathrm{Y}$ if $\mathrm{Z}$ occurs". Unlike a regular contract where after reaching an agreement, parties must execute the contract for it to take place, a smart contract is self-executing-that is, once the instructions are written to a blockchain, the transaction will take place automatically when the appropriate conditions are detected, with no further actions required by the parties to the transaction or other third parties [38]. In other 


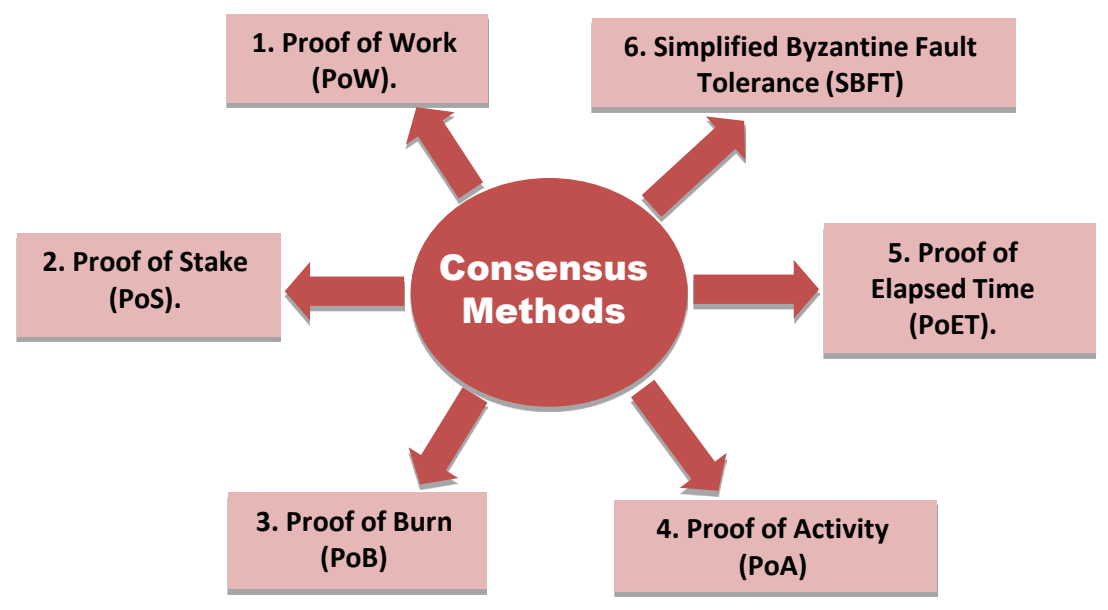

Figure 5. Consensus methods.

words, it can be said that the smart contracts are computer protocols that facilitate, verify or enforce the execution of a contract. At a fundamental level, smart contracts are analogous to a series of if-then statements applied to the details of a transaction [39]. Figure 6 illustrates how a smart contract works [40]. There are various benefits of using smart contracts but reducing transaction costs and increased transparency are the two key elements achieved by increasing digital efficiency by eliminating the need for mediators.

\subsection{Requirements for Blockchain Environment}

A smart city can have vastly different requirements for different use cases and scenarios, which needs high levels of trust, save time and cost, security, and etc. To address this diversity, basic requirements must be met for blockchain as shown below:

- A peer-to-peer network which is either public, partially or totally private.

- A distributed database acting as a ledger, where all transactions and other relevant information are recorded for network members.

- A variety of tools and cryptographic processes ensuring the security of the network and the integrity of exchanges among its members.

- A consensus algorithm managing the updating of the ledger and allowing for the process of validation of transactions among the members of the network to be automated through a variety of procedural rules.

- An incentive mechanism embedded in the network's operating protocol, which is necessary for rewarding the most active members of the network-that is, those who take responsibility for ensuring that the network works correctly and is secure, especially if the network is completely open.

\subsection{Blockchain Mechanism}

Blockchain is, simply put, an electronic ledger system managed without a central authority by a distributed network of independent computers, called "nodes" (Figure 7). At their most basic level, blockchain enables users to record digital 


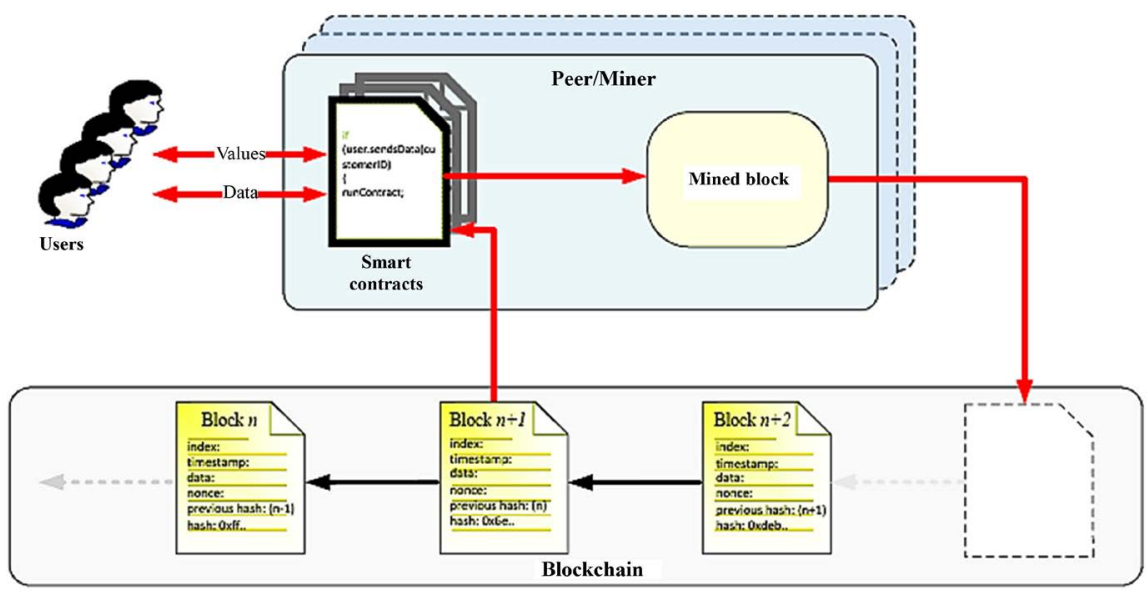

Figure 6. How a smart contract works.

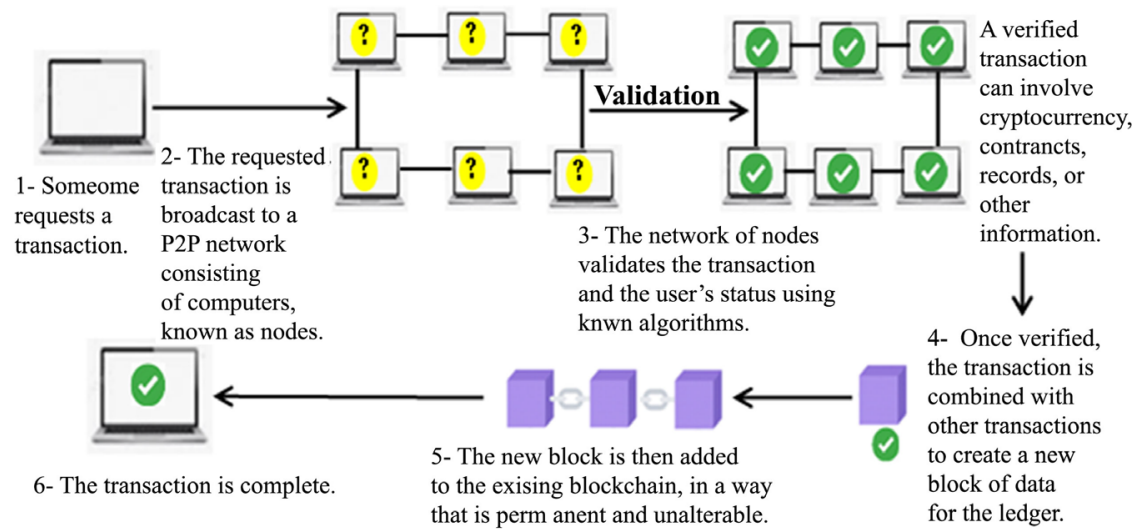

Figure 7. Blockchain mechanism.

transactions without the risk of third-party interference or alteration. New transactions are sent to a node informing the computer network of the pending transaction. A node is randomly selected to review the details of the pending transaction and determine its legitimacy using rules established by the blockchain's design. To maximize efficiency, many transactions are bundled together by nodes into a block and are then added to the chain. All nodes receive an updated copy of the blockchain and there exists no "master" version [20].

\subsection{Blockchain Applications}

Although blockchain is quite a new technology, it can be widely used in industry with many use cases in the new solutions that are constantly introduced. A survey conducted by the World Economic Forum in 2015 predicts that $10 \%$ of global GDP will be stored in blockchain technology by 2027 [41]. The next paragraphs show some applications of blockchain technology in a smart city field [16] [19] [42] [43].

\section{Identity services}

Many startups are already working on blockchain technology to identify services. Identity detection based on blockchain technology can be used effectively 
for managing passports, birth and wedding certificates, national and electoral identity, and managing e-residency programs, among others. However, there are critics who claim that existing digital ID technologies work well and are more scalable than those using blockchain platforms. Indeed blocking the scalability limits of blockchain technology could block the massive deployment of countries with large populations such as India and China.

\section{Governmental services}

Blockchain can be used to support the provision of public needs to citizens and stakeholders, especially those who require personal interaction and need personal identification. An implicit link between blockchain technology and e-Government exists, and this link is exploited by a series of startup blocks. Thus, the delivery of selected and personalized governmental services will be possible using this technology.

\section{Education}

Student records, faculty records, educational certificates, etc., are key assets in the education domain. Such records need to be shared with multiple stakeholders and it is imperative to ensure that they are trustworthy. The provenance of these records also needs to be determined accurately. Student records, faculty records, and educational certificates can be maintained with the application of blockchain technology. Blockchain can also simplify certificate attestation and verification. It could even transform the manner in which the policy for educational inclusion is framed by bringing in base uniformity in the tracking of national metrics.

\section{Financial services}

Cryptocurrencies and blockchain can universally rectify the situation, which resulted from the current financial industry. With a smartphone and an internet connection, both of which are widely available, anyone can bank, start a business and receive payments.

\section{Publishing}

An example of a rather unexpected application of blockchain, the publishing industry too can benefit from decentralization. A platform like an authorship is set to overturn the current system, where influence is in the hands of publishers, by using a tokenized system that recognizes the work of any writer. Publishers can choose to digitally publish writers and print their books, should they feel convinced of their quality and should demand to exist.

\section{Elections}

Various types of electoral processes have also benefited from the implementation and use of blockchain technologies. Distributed registers can be used to run voting processes and prevent fraud and identity theft. One of the potential advantages is that voters using blockchains can check their voting choices using their private keys at any time. For example, Ukraine is the country that will use e-vox, a distributed registry based on Ethereum for local elections. Implementation has already begun in several cities. However, one of the main issues is access to private keys that hackers might acquire in a variety of ways, or voters could 
offer loans or sell their private keys in economic interest. Once it appears to be a viable method, it will be interesting to compare voting in the blockchain with the Internet vote, which is already used in Estonia.

\section{Aid and development}

Aid Tech, a London company, is probably the first launch of blockchain technology that has supported humanitarian and development efforts in the Middle East. The company offers a voucher system that can be used even in the most difficult contexts and helps ensure that financial resources are safe in the final destination. Bitnation now also provides support for refugees.

\section{Healthcare}

Patient data is a crucial part of the medical industry. Secure storage and data access, which could protect and make an efficient diagnosis, is possible with blockchain. With a view to reaching improve the healthcare space by offering a secure space for stakeholders to store and manage data. Their target audience is patients, providers and healthcare organizations. Patients can easily access their data and hand it over to providers, who may not have a complete history of the patient's health but will be able to view notes from previous providers and organizations. The organizations benefit from cheaper, secure and efficacious record storage.

\section{Supply chain management}

The supply chain industry is one fraught with many challenges, most of which are concerned with curtailing rising costs and efficiently supplying products to retailers and customers. The industry faces several intractable obstacles. Fuel costs are ever on the rise, which makes transportation an increasingly expensive activity. Overproduction of products wastes precious resources like water and electricity, as well as taking up space and eventually becoming harmful waste. Smart contracts offer a potential solution to this problem. With smart contracts, it is possible for funds to be locked into a contract, whereupon manufacturers would begin production only after a certain number has been reached. It would eliminate the worry of overestimating demand and resource consumption, and could also eliminate middlemen by directly connecting consumers with manufacturers.

\section{Internet of things}

Along with blockchain and artificial intelligence, the Internet of Things is another technological development that is up and coming, with radical transformative effects. Combining RFID technology with blockchain and the Internet of Things to form what they call the "Value Internet of Things", a new business system will evolve where logistics, manufacturing, retail, and infrastructure can share data securely. Because of RFID technology, the system will also feature product traceability and asset ownership.

\section{Cloud computing/ distributed computing}

Computing power is quickly becoming a fundamental necessity, like electricity and the internet. Many of the tasks that we do today, and certainly those in the scientific and entertainment industries, require heavy computation. The 
trouble is that it requires resources that are currently only accessible to major corporate powers who have the funds to operate power systems. The distributed nature of blockchain lets any user across the world utilize the computing power of ordinary computers to perform computationally-intensive tasks.

\section{Construction industry}

The fundamental concept that can enable the combination of BIM and blockchain technology is their shared ability to serve as a single source of truth. BIM can combine information from the blockchain, such as supply chain information, the provenance of materials, payment details, etc. particularly during construction; and, it can also assign information to the blockchain, like design decisions, source of data or model modification orders. This information can later be used by smart contracts to initiate further action, such as payments or material orders. The French start-up BIMCHAIN is developing a similar blockchain application that was described above. The main concept is to deploy blockchain together with BIM processes and data making the BIM data and model contractual. Through smart contracts, BIMCHAIN would like to validate models, initiate automatic payments and enhance collaboration with blockchain enabled proof of consistency, publication, and approval. The project developed plugins for software such as ArchiCAD and Revit in order to integrate its blockchain solution to the main Autodesk BIM software. A Beta Program is launched in December 2018 in order to support the development of the company's first product.

\section{Insurance}

The insurance market has several layers of intermediaries, making approval a frustrating chore. The process is inefficient and lacks ease of communication. Blockchain's goal is to encourage new business models, increase transaction speed and insurance approval, reduce risk through better data access, and improve customer experience.

\section{Blockchain-as-a-service}

Software is the backbone of every computing device, from the smartphone to the personal computer. The modular nature of it has helped many a developer create even more software. Some projects offer end-to-end solutions for software development, making testing and deployment on the blockchain simpler. They also feature an academy where one can learn about development. Essentially, it is a Software-as-a-Service platform that provides blockchain utility to its users.

\section{Digital advertising}

The power to reach an audience and influence them has always been with those with the largest amount of money. This results in numerous problems, not the least of which is centralized advertising power. Users are bombarded with irrelevant and frequent advertisements. Data is collected and exploited to further target individuals.

\section{Energy}

The energy industry is also hampered by middlemen. Blockchain technology could change that by letting individuals buy and sell energy through smart con- 
tracts. The energy used by individuals in homes could form a micro grid where communities become resilient to power outages, as well as reduce the drain on the environment.

\section{Human resources/recruitment}

Tamper-proof ledgers that safely store personal data while simultaneously allowing them to be easily accessed makes blockchain ideal for use in a field like human resources, where the verification of employee data can be time-consuming and laborious. It would make hiring more efficient and streamline all of the tangential processes associated with HR, such as setting up an employee bank account and medical benefits.

\section{Examples of Blockchain's Experiments}

Nowadays, we can find that so many blockchain projects underway in so many countries. Moreover, the speed of expansion of government-led blockchain projects worldwide is astonishing. For example, Estonia has used blockchain technology to issue e-ID for identity verification for their citizens. Additionally, electronic voting systems based on blockchain are being built in many countries including Ukraine, Estonia, and Australia. The United States is working to incorporate blockchain technology to record and share medical information, and the UK is pursuing research and development to apply blockchain technology to public services. Dubai wants to move many government transactions into blockchain by 2020. The Swiss city of Zug uses blockchain to digitize ID registration and is working on e-voting. Zug also accepts cryptocurrency as payment for public services. China has announced a plan to build a "Blockchain city", based on blockchain technology. Table 5 summarizes examples of government-led blockchain projects [44].

\section{Evaluation of Blockchain Technology}

Several benefits of the blockchain technology in smart city are highlighted including the reduced transaction cost, speedy process, enhanced privacy and reliability. As a blockchain is a specific type of distributed ledger shared within a network, it is not owned by one person or organization. Unlike traditional transactions where a trusted third party is needed to verify and certify the transaction, the blockchain technology does not require a middleman that verifies the accuracy or the authenticity of the transaction, thus, reducing its transaction cost. Table 6 shows the key benefits of blockchain technology in a smart city [45]. The main challenges facing blockchain involve [46]:

- Lack of clarity on the terminology and perceived immaturity of the technology.

- Perceived risks in early adoption and likely disruption to existing industry practices.

- Insufficient evidence on business gains and wider economic impact.

- Lack of clarity on how the technology is/would be governed. 
Table 5. Examples of government-led blockchain projects.

\begin{tabular}{|c|c|c|}
\hline Country & Project & Status \\
\hline & $\begin{array}{l}\text { 1) Australian senators launch parliamentary } \\
\text { friends of blockchain group. }\end{array}$ & Announced in August 9, 2017. \\
\hline Australia & $\begin{array}{l}\text { 2) The Australian Securities Exchange } \\
\text { announced that they will use blockchain } \\
\text { technology to clear and settle trades by } \\
\text { replacing the outdated Clearing House } \\
\text { Electronic Sub register System. }\end{array}$ & $\begin{array}{l}\text { Announced in December, 2017. The } \\
\text { proposed transition is expected to } \\
\text { take place in March } 2018 .\end{array}$ \\
\hline \multirow{6}{*}{ China } & 1) Social security funds management system. & Announced in 2016. \\
\hline & 2) Mortgage valuations on blockchain. & Announced in 2016. \\
\hline & 3) Blockchain-based asset custody system. & $\begin{array}{l}\text { Successfully executed more than } 100 \\
\text { real business transactions on the }\end{array}$ \\
\hline & & $\begin{array}{l}\text { blockchain since the system went live } \\
\text { in October } 2016 .\end{array}$ \\
\hline & 4) Blockchain city project (By Wanxiang & The project was announced by \\
\hline & Group). & $\begin{array}{l}\text { Wanxiang Group in } 2016 \text { and backed } \\
\text { by Chinese government. }\end{array}$ \\
\hline \multirow{3}{*}{ Dubai } & $\begin{array}{l}\text { 1) Government documents management } \\
\text { system to be enacted by } 2020 \text {. }\end{array}$ & Ongoing. \\
\hline & $\begin{array}{l}\text { 2) Global blockchain council was established in } \\
2016 \text { with } 32 \text { members, including government } \\
\text { entities, international companies, leading UAE } \\
\text { banks, free zones, and international blockchain } \\
\text { technology firms. }\end{array}$ & Ongoing. \\
\hline & $\begin{array}{l}\text { 3) Digital passport based on blockchain. } \\
\text { 4) Real-time information system about } \\
\text { shipments to Dubai. }\end{array}$ & $\begin{array}{l}\text { Announced in June } 2017 . \\
\text { Announced in } 2017 .\end{array}$ \\
\hline \multirow{3}{*}{ Estonia } & 1) eID (electronic ID management system). & $\begin{array}{l}\text { The government is currently } \\
\text { upgrading the existing system with } \\
\text { blockchain technology. }\end{array}$ \\
\hline & $\begin{array}{l}\text { 2) E-health (medical information management } \\
\text { system). }\end{array}$ & $\begin{array}{l}\text { The government is currently } \\
\text { upgrading the existing system with } \\
\text { blockchain technology. }\end{array}$ \\
\hline & $\begin{array}{l}\text { 3) The government is currently upgrading the } \\
\text { existing system with blockchain technology. }\end{array}$ & $\begin{array}{l}\text { Since } 2015 \text {, more than } 27,000 \text { people } \\
\text { from } 143 \text { countries have applied and } \\
4272 \text { companies have been } \\
\text { established as of December } 2017 \text {. }\end{array}$ \\
\hline Ghana & Land title registry project by NGO "Bitland". & Ongoing. \\
\hline Georgia & Land title registry project. & Ongoing. \\
\hline Honduras & Land title registry project. & $\begin{array}{l}\text { Announced in } 2015 \text { and known as } \\
\text { failure now. }\end{array}$ \\
\hline \multirow{3}{*}{ Russia } & $\begin{array}{l}\text { 1) Blockchain based documents management } \\
\text { system announced by Moscow government. }\end{array}$ & Announced in 2016. \\
\hline & & \\
\hline & $\begin{array}{l}\text { 2) Russia's ministry of health is launching a } \\
\text { blockchain pilot. }\end{array}$ & Announced in Aug 10, 2017. \\
\hline Singapore & Cross-border interbank payments. & $\begin{array}{l}\text { A proof-of-concept project has been } \\
\text { initiated in } 2016 .\end{array}$ \\
\hline Sweden & $\begin{array}{l}\text { Trials of a blockchain smart contracts } \\
\text { technology for land registry. }\end{array}$ & Tested in early 2017. \\
\hline
\end{tabular}




\section{Continued}

1) The city of Zug (the capital of the canton of Since July 2016 (Crypto Valley was Zug) started accepting Bitcoin as payment for city fees. The large number of companies named by Ethereum co-founder Mihai Alisie).

Switzerland engaged in cryptocurrency is located in Crypto Valley in Zug.

2) Zug offers blockchain-based digital identity Announced in 2017. to their residents.

Ukraine

E-vox (Ethereum blockchain-based election platform).

Announced in 2016

1) The UK government's Department of Work Announced in July 2016 and and Pensions tested an experiment in which a successfully finished trail system. blockchain system is used to distribute welfare

United payments.

Kingdom 2) Blockchain as a service for each government Available since August 2016. (UK) department.

3) Blockchain-based digital currency.

UK's Financial Conduct Authority permitted blockchain startup,

4) Blockchain-based payment system between Tramonex, to issue digital money. banks. Announced in 2017.

1) Pilot project for secure exchange of personal A two-year agreement for the tests health data online. was announced in 2016.

2) Approving plan to issue stock via Bitcoin's Announced in 2015.

blockchain (Securities and Exchange

Commission).

United

3) Arizona bill to make blockchain smart

States (US) contracts "legal".

Officially became state law in March

4) Governor of Delaware has officially signed a Announced in July 2017.

bill making it explicitly legal for those entities

to use blockchain for stock trading and

record-keeping.

5) Illinois launches blockchain pilot to digitize Announced in Aug 31, 2017.

birth certificates.

Table 6. Key benefits of the blockchain technology in smart city.

\begin{tabular}{|c|c|}
\hline Benefit & Description \\
\hline Reliable and available & $\begin{array}{l}\text { Since multiple participants share a blockchain, it has no single point of failure } \\
\text { and is thus resilient to attacks. }\end{array}$ \\
\hline Immutable & $\begin{array}{l}\text { It is nearly impossible to make changes to a blockchain without detection, } \\
\text { thus reducing chances of fraud. }\end{array}$ \\
\hline Irrevocable & $\begin{array}{l}\text { It is possible to make records irrevocable, which can increase accuracy and } \\
\text { simplify back-end processes. }\end{array}$ \\
\hline Near real time & It provides unbroken and timely record of information. \\
\hline Saves costs & $\begin{array}{l}\text { Since there is no third party or intermediary (banks, legal institution, } \\
\text { government) involved, blockchain can cut down costs. }\end{array}$ \\
\hline Transparency & $\begin{array}{l}\text { The consensus mechanisms provide the benefits of a consolidated, consistent } \\
\text { dataset with reduced errors. }\end{array}$ \\
\hline
\end{tabular}

- Uncertainty around regulation.

- Multiple non-interoperable implementations and resulting fragmentation.

- Maintaining security and privacy of data. 
- Ensuring the integrity of data and strong encryption.

- Energy-intensive nature of the technology.

- Lack of clarity regarding smart contracts and how to implement them through DLT/Blockchain.

The blockchain technology operates in a multidimensional way. Different authors usually highlight different aspects of it or describe the same aspect with different terms. There seems, however, to be a consensus around four central properties of blockchain technology [47]. Table 7 shows the most salient characteristics of the blockchain protocol. It involves the strengths factors in opposite to weakness ones. In addition, opportunities are listed against threats.

\section{Conclusion}

The smart city faces various challenges. Some of the most significant challenges are related to the increased amount of data transfer and ensuring security. This study introduces the capabilities of using novel blockchain technologies that can mitigate challenges by taking advantage of the opportunities and benefits of blockchain and other new technologies. Blockchain technology has enormous potential when it comes to shaping the enhanced smart communities in the future in ways that are more efficient and provide a better quality of living. For technology to deliver on its promise, it must be allowed to change the current situation, replaced, and will be replaced through innovation. This study also explains how blockchain-based sharing services can help create smart cities, and discusses the concepts and foundations of blockchain, as well as key blockchain technology applications. Clear examples of the practical use of this technique are

Table 7. The most salient characteristics of the blockchain protocol.

\begin{tabular}{|c|c|}
\hline Strengths & Weaknesses \\
\hline $\begin{array}{l}\text { - Distributed resilience and control. } \\
\text { - Decentralized network. } \\
\text { - Open source. } \\
\text { - Security and modern cryptography. } \\
\text { - Asset provenance. } \\
\text { - Native asset creation. } \\
\text { - Dynamic and fluid value exchange. }\end{array}$ & $\begin{array}{l}\text { - Lack ledger interoperability. } \\
\text { - Customer unfamiliarity and poor user experience. } \\
\text { - Lack of intraledger and interledger governance. } \\
\text { - Lack of hardened/tested technology. } \\
\text { - Limitation of smart contract code programming } \\
\text { - model. } \\
\text { - Waller and key management. } \\
\text { - Poor tooling and poor developer user experience. } \\
\text { - Immature scalability. } \\
\text { - Lack of trust in new technology suppliers. }\end{array}$ \\
\hline Opportuni & Threats \\
\hline $\begin{array}{l}\text { - Reduced transaction costs. } \\
\text { - Business process acceleration and efficiency. } \\
\text { - Reduced fraud. } \\
\text { - Reduced systemic risk. } \\
\text { - Monetary democratization. } \\
\text { - New business-model enablement. } \\
\text { - Application rationalization and redundancy. }\end{array}$ & $\begin{array}{l}\text { - Legal jurisdictional barriers. } \\
\text { - Politics and hostile nation-state actors. } \\
\text { - Technology failures. } \\
\text { - Institutional adoption barriers. } \\
\text { - Divergent blockchains. } \\
\text { - Ledger conflicts/competition. } \\
\text { - Poor governance. }\end{array}$ \\
\hline
\end{tabular}


represented in the experience of different countries in different sectors. It shows the oldest successful, comprehensive and continuous experiments, which provide a clear perception of the advantages and benefits as well as the challenges that can face the implementation of such technology in other contexts.

\section{Conflicts of Interest}

The authors declare no conflicts of interest regarding the publication of this paper.

\section{References}

[1] PwC and FICCI (2015) India: Surging to a Smarter Future. https://www.pwc.in/assets/pdfs/publications/2015/india-surging-to-a-smarter-futur e.pdf

[2] Nãsulea, C. and Mic, S. (2018) Using Blockchain as a Platform for Smart Cities. University of Bucharest, Bucharest.

[3] Ghassan, K. (2016) On the Security and Scalability of Bitcoin's Blockchain. Proceedings of the 2016 ACM SIGSAC Conference on Computer and Communications Security, Vienna, Austria, 24-28 October 2016, 1861-1862.

[4] National League of Cities (2016) Trends in Smart City Development. https://www.nlc.org/sites/default/files/2017-01/Trends\%20in\%20Smart\%20City\%20 Development.pdf

[5] Abbas, R. (2017) A Comparison of Smart City Indicators for Three Top Ten US Cities. Master Thesis, The University of Texas at Arlington, Arlington, TX. https://rc.library.uta.edu/uta-ir/bitstream/handle/10106/26843/ABBAS-THESIS-201 7.pdf? sequence $=1$ \&isAllowed $=y$ September

[6] Antonsen, H. (2017) Platform Infrastructure as a Driver of Smart City Development. Master Thesis. University of Oslo, Norway.

https://www.datek.no/dv-cms/resources/masterhaakoaan-1.pdf

[7] Carnevale, M.J. (2017) Toronto Augmented Reality Map: Enhancing Citizen Engagement with Open Government Data Using Contemporary Media Platforms. Master Thesis, OCAD University, Toronto. http://openresearch.ocadu.ca/id/eprint/1680/

[8] Gabrielle, F. (2017) The Origin and Implementation of the Smart-Sustainable City Concept the Case of Malmö-Sweden. Master Thesis, Lund University, University of Manchester and University of the Aegean. Sweden, Manchester, Lesvos, Greece.

[9] Jessen, J. (2015) How to Create a Smart City? Co-Creation of a Smart City with Citizens. Master Thesis, Eindhoven University, Holland. http://www.digitalbydel.dk/wp-content/uploads/2015/01/MA_Guenter_final.pdf

[10] Shahi, K. (2018) Evaluation of Current Construction Permitting Process in City of Toronto and Future of Permitting in the Global Construction Industry. Master Thesis, University of Toronto, Toronto, Canada.

[11] Song, Y., Wang, X., Yi, T., Wu, P., Sutrisna, M. and Cheng, J. (2017) Trends and Opportunities of BIM-GIS Integration in the Architecture, Engineering and Construction Industry: A Review from a Spatio-Temporal Statistical Perspective. ISPRS International Journal of Geo-Information, 6, 397. https://doi.org/10.3390/ijgi6120397

[12] Zhang, X., Arayici, Y., Wu, S., Abbott, C. and Aouad, G. (2009) Integrating BIM 
and GIS for Large Scale (Building) Asset Management: A Critical Review. Paper for CC2009, School of the Built Environment, University of Salford, Salford, Greater Manchester.

[13] Alastal, A.I., Salha, R.A. and El-Hallaq, M.A. (2019) The Reality of Gaza Strip Cities towards the Smart City's Concept. A Case Study: Khan Younis City. Current Urban Studies, 7, 143-155. https://doi.org/10.4236/cus.2019.71006

[14] El-Hallaq, M.A., Alastal, A.I. and Salha, R.A. (2019) Enhancing Sustainable Development through Web Based 3D Smart City Model Using GIS and BIM. Case Study: Sheikh Hamad City. Journal of Geographic Information System, 11, 321-330. https://doi.org/10.4236/jgis.2019.113019

[15] Tapscott, D. and Tapscott, A. (2016) Blockchain Revolution: How the Technology behind Bitcoin Is Changing Money, Business, and the World. Penguin, New York. https://www.amazon.com/Blockchain-Revolution-Technology

[16] Penzes, B. (2018) Blockchain Technology in the Construction Industry: Digital Transformation for High Productivity. Institution of Civil Engineers (ICE), London. https://www.ice.org.uk/ICEDevelopmentWebPortal/media/Documents/

[17] Shen, C. and Pena-Mora, F. (2018) Blockchain for Cities-A Systematic Literature Review. IEEE Access, 6, 76787-76819. https://doi.org/10.1109/ACCESS.2018.2880744c

[18] Pieroni, A., Scarpato, N., Di Nunzio, L., Fallucchi, F. and Raso, M. (2018) Smarter City: Smart Energy Grid Based on Blockchain Technology. International Advanced Science Engineering Information Technology, 8, 298-306. https://doi.org/10.18517/ijaseit.8.1.4954

[19] Yannis, k. (2017) Blockchain \& Smart Contracts Building Blocks for Smart Cities. Orange Business Services. https://www.decentralized.com/wp-content/uploads/2017/12/John-Karamitsos-Bloc kchain-Smart-Contracts-Building-blocks-for-Smart-Cities.pdf

[20] Energy Futures Initiative (2018) Promising Blockchain Applications for Energy: Separating the Signal from the Noise. Policy Paper, Washington DC.

[21] Wright, O. and Wright, W. (1906) Flying-Machine. US Patent No. 821393.

[22] Biswas, K. and Muthukkumarasamy, V. (2016) Securing Smart Cities Using Blockchain Technology. Technical Report, Kaspersky Lab, Griffith University, Brisbane, 1-22.

[23] Sogeti Labs (2014) IBM’s Smarter Cities Challenge: A 5-Year Evaluation. https://labs.sogeti.com/ibms-smarter-cities-challenge-5-year-evaluation/

[24] Chourabi, H., Nam, T., Walker, S., Mellouli, S., Nahon, K., Pardo, T. and Scholl, H. (2012) Understanding Smart Cities: An Integrative Framework. 2012 45th Hawaii International Conference on System Sciences, Maui, HI, 4-7 January 2012, 2289-2297. https://doi.org/10.1109/HICSS.2012.615

[25] National League of Cities (2016) Blockchain in Cities: Restoring Trust and Transparency Digital Transactions.

https://www.nlc.org/sites/default/files/2018-06/CSAR_Blockchain\%20Report\%20PR INT.pdf

[26] Vineet, M. (2017) An Approach to Recovery of Critical Data of Smart Cities Using Blockchain. Master Thesis, University of Toronto, Toronto, Canada.

[27] Washburn, D., Sindhu, U., Balaouras, S., Dines, R.A., Hayes, N.M. and Nelson, L.E. (2010) Helping CIOs Understand "Smart City" Initiatives: Defining the Smart City, Its Drivers, and the Role of the CIO. Forrester Research, Inc., Cambridge, MA. http://public.dhe.ibm.com/partnerworld/pub/smb/smarterplan 
[28] Robby, H. and Alexander, S. (2018) Cryptocurrencies and Blockchain: Legal Context and Implications for Financial Crime, Money Laundering and Tax Evasion. European Parliament's Special Committee on Financial Crimes, Tax Evasion and Tax Avoidance.

[29] Holotescu, C. (2018) Understanding Blockchain Technology and How to Get Involved. The 14th International Scientific Conference eLearning and Software for Education, Bucharest, 19-20 April 2018, 1-22.

[30] Bahga, A. and Madisetti, V. (2016) Blockchain Platform for Industrial Internet of Things. Journal of Software Engineering and Applications, 9, 533-546. https://doi.org/10.4236/jsea.2016.910036

[31] Government Office for Science (2016) Distributed Ledger Technology: Beyond Block Chain. A Report by the UK Government Chief Scientific Advisor. London.

[32] Garrick, H and Michel, R. (2017) Global Blockchain Benchmarking Study. Cambridge Centre for Alternative Finance, Cambridge.

[33] Abid, S., Muhammad, A. and Azhar, M. (2018) Internet of Things Security Issues and their Solutions with Blockchain Technology Characteristics: A Systematic Literature Review. American Journal of Computer Science and Information Technology, 6, 27. https://doi.org/10.21767/2349-3917.100027

[34] Zheng, Z., Xie, S., Dai, H., Chen, X. and Wang, H. (2017) An Overview of Blockchain Technology: Architecture, Consensus, and Future Trends. 2017 IEEE International Congress on Big Data, Honolulu, HI, 25-30 June 2017, 557-564.

[35] Timothy, L. (2017) Blockchain for Transportation: Where the Future Starts. White Paper Blockchain for Transportation, a Trimble Company, Sunnyvale, CA. https://www.tmwsystems.com/sites/default/files/TMW_Blockchain-WhitePaper_9. 12.17.pdf

[36] IAB Tech Lab (2018) Blockchain Technology Primer, Version 1.0. https://iabtechlab.com/wp-content/uploads/2018/07/Blockchain-Technology-Prime r.pdf

[37] Winter Green Research (2018) Blockchain Market Shares, Market Strategies, and Market Forecasts, 2018 to 2024. WinterGreen Research, Inc., Lexington, MA.

[38] Grech, A. and Camilleri, F. (2017) Blockchain in Education. Publications Office of the European Union, Luxembourg.

[39] PwC (2018) Fourth Industrial Revolution for the Earth Series: Building Block (Chain)s for a Better Planet.

https://www.pwc.com/gx/en/sustainability/assets/blockchain-for-a-better-planet.pd $\underline{\mathrm{f}}$

[40] Jovović, I., Husnjak, S., Forenbacher, I. and Maček, S. (2019) Innovative Application of 5G and Blockchain Technology in Industry 4.0. EAI Endorsed Transactions on Industrial Networks and Intelligent Systems, 6, No. 18. https://doi.org/10.4108/eai.28-3-2019.157122

[41] Dylan, Y., Peter, M., Nik, R. and Karen, S. (2018) Blockchain Technology Overview. National Institute of Standards and Technology Internal Report No. 8202. https://doi.org/10.6028/NIST.IR.8202

[42] Rebrisoreanu, M., Rus, C., Leba, M. and Ionica, A. (2018) Exploring the Possibilities of Blockchain Use in a Smart City. International Journal of Systems Applications, Engineering \& Development, 12, 164-167.

[43] Abhimanyu, K. (2018) 24 Industries That Blockchain Will Radically Transform. https://www.investinblockchain.com/blockchain-transform-industries/ 
[44] Jun, M.S. (2018) Blockchain Government-A Next Form of Infrastructure for the Twenty-First Century. Journal of Open Innovation: Technology, Market, and Complexity, 4, 7 .

[45] Deloitte and FICCI (2018) Blockchain in Public Sector: Transforming Government Services through Exponential Technologies.

https://www2.deloitte.com/content/dam/Deloitte/in/Documents/public-sector/in-p s-blockchain-noexp.pdf

[46] Deshpande, A., Stewart, K., Lepetit, L. and Gunashekar, S. (2017) Distributed Ledger Technologies/Blockchain: Challenges, Opportunities and the Prospects for Standards. British Standards Institution.

https://www.bsigroup.com/LocalFiles/zh-tw/InfoSec-newsletter/No201706/downloa d/BSI_Blockchain_DLT_Web.pdf

[47] Witzig, P. and Salomon, V. (2018) Cutting out the Middleman: A Case Study of Blockchain-Induced Reconfigurations in the Swiss Financial Services Industry. 